\title{
Voltammetric Properties of Nickel Hexacyanoferrate (III) Obtained on the Titanium (IV) Silsesquioxane Occluded into the H-FAU Zeolite for Detection of Sulfite
}

\author{
Devaney Ribeiro do Carmo ${ }^{1}$ • Vitor Alexandre Maraldi ${ }^{1} \cdot$ Loanda Raquel Cumba $^{1}$
}

Received: 9 February 2018 / Accepted: 24 May 2018 / Published online: 31 May 2018

(C) Springer Science+Business Media B.V., part of Springer Nature 2018

\begin{abstract}
A composite prepared from titanium (IV) silsesquioxane and phosphoric acid (TTiP) was prepared and occluded into the HFAU zeolite (ZTTiP). The material was chemically modified with nickel and subsequently by potassium hexacyanoferrate (III) (ZTTiPNiH). It was preliminarily characterized by infrared spectroscopy (IR), energy dispersive X-ray spectroscopy (EDS) and cyclic voltammetry (CV). The voltammetric behavior of ZTTipNiH was obtained employing a modified graphite paste electrode (GPE) showing one well-defined redox couple with a formal potential of $\mathrm{E}^{\theta^{\prime}}=0.51 \mathrm{~V}(\mathrm{vs} \mathrm{Ag} / \mathrm{AgCl}(\mathrm{sat}))$, $\mathrm{KCl}(3 \mathrm{M})\left(20 \% \mathrm{w} / \mathrm{w} ; v=20 \mathrm{mV} \mathrm{s}^{-1} ; \mathrm{KCl} ; 1.00 \mathrm{~mol} \mathrm{~L}{ }^{-1}\right)$ corresponding to the $\mathrm{Ni}^{\mathrm{II}} \mathrm{Fe}^{\mathrm{II}}(\mathrm{CN})_{6} / \mathrm{Ni}^{i \mathrm{II}} \mathrm{Fe}^{\mathrm{III}}(\mathrm{CN})_{6}$ redox process. After rigorous voltammetric studies, the GPE modified with ZTTiPNiH was applied for facile and rapid detection of sulfite. From the analytical curve, a linear response was obtained in a concentration range of 0.05 to $0.80 \mathrm{mmol} \mathrm{L}^{-1}$ and a detection limit $(3 \sigma)$ of $0.05 \mathrm{mmol} \mathrm{L}^{-1}$ with a relative standard deviation of $4.21 \%(\mathrm{n}=3)$ and an amperometric sensitivity of $14.42 \mathrm{~mA} \mathrm{~L} \mathrm{~mol}^{-1}$ for sulfite.
\end{abstract}

Keywords Silsesquioxanes $\cdot$ Titanium (IV) silsesquioxane $\cdot$ Zeolite $\cdot$ Nickel hexacyanoferrate (III) $\cdot$ Voltammetry $\cdot$ Sulfite

\section{Introduction}

Silsesquioxane refers to any compound in which the ratio of $\mathrm{Si}$ to $\mathrm{O}$ is 1.5 , meaning that silicon is trivalent toward oxygen, leaving its fourth valency to another substituent, typically $\mathrm{H}$ or an organic group. It results in a general formula of $\left(\mathrm{RSiO}_{1.5}\right)_{\mathrm{n}}$ (for integer oxygen numbers, $\mathrm{n}$ must be an even number) $[1,2]$. This also includes polymeric and resinous materials. These materials are designated polyhedral oligomeric silsesquioxanes (POSS) if $n=4,6,8$, $10 ;(n>4)[3,4]$. The POSS is the most interesting class of molecular silsesquioxanes, these compounds can be divided into completely condensed structures, and incompletely condensed structures, containing silanol groups and being of a more complex general formula [3, 4].

The most important and studied incomplete condensed silsesquioxanes are the trisilanol POSS (Fig. 1). It has been

Devaney Ribeiro do Carmo

docarmo@dfq.feis.unesp.br

1 Departamento de Física e Química, Faculdade de Engenharia de Ilha Solteira, UNESP - Universidade Estadual Paulista, Av. Brasil Centro, 56, CEP 15385-000, Ilha Solteira, SP, Brazil found that the interaction of trisilanol POSS with transition metals [4-8] form materials that presenting the same heterogeneous characteristics of inorganic functionalized silica with transition metals. This materials exhibit electrodedonor sites [8] and allow interactions with the donator neighboring oxygen that increases the stability of the clusters $[9,10]$. Additionally, the demarcated alignment of the hydroxyl $(\mathrm{OH})$ groups on the surface [11] contributes to the selectivity at which the reactant reacts on the surface [17].

The most striking recently applications of incompletely condensed POSS are those related to technological importance, such as photocatalysis [12], capturing of $\mathrm{CO}_{2}$ [13], dispersants for pigment treatment [14], building blocks, polymers [15] and especially, homogenous and heterogeneous catalysis [16]. Recently was demonstrated [17], that the titanium (IV) silsesquioxane (TS) structure remained unchanged when occluded.

The present work aims to occlude the cubic TS into the cavities of FAU zeolite. The coordination of titanium (IV) into a silsesquioxane structure tends to produce an electrophilic metallic center $[4,17]$ conducive to different interactions. In addition, FAU zeolites present high porosity and surface area, which are of great essential to the employment in the 
Fig. 1 Scheme of corner capping reaction of cyclohexyl trisilanol-POSS with titanium (IV) isopropoxide

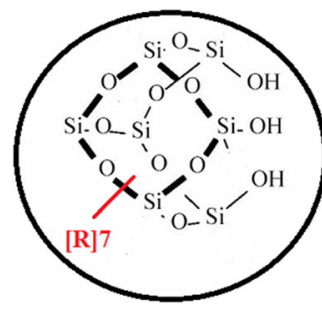

(1)
$\mathrm{R}=c-\mathrm{C}_{6} \mathrm{H}_{11}$ construction of electrodes, especially concerning its use as

The modifications of zeolites with incompletely condensed silsesquioxanes are not commonly studied mainly for electroanalysis purposes. In this study, the occluded TS was phosphated into the H-FAU zeolite. The modified zeolite after reaction of Nickel and subsequent metal complex formation with potassium hexacyanoferrate (III) (ZTTipNiH was applied for facile and rapid detection of sulfite.

Sulfite is a potentially toxic compound that is widely used as a legal food additive employed in the prevention of microbial spoiling and darkening reactions across a wide range of products [19]. High levels of this substance can drive adverse reactions in asthma patients [20] and several changes in the organoleptic properties of consumables [21, 22]. In this context, food products containing more than the limit established by legislation must be accurately labeled and methods that allow an accurate measurement of sulfite is highly important for the food industry.

The methods commonly used for determination of sulfite are titration [23, 24], spectrophotometry [25, 26], ion chromatography [27], high-performance liquid chromatography (HPLC) $[28,29]$, and voltammetry [3032]. However, the high cost, time-consuming and necessity of sample pretreatment make most of the techniques disadvantageous, excepting voltammetry.

\section{Experimental}

\subsection{Reagents and Solutions}

The reagents utilized in the synthesis were of high analytical purity. The molecular sieve (H-FAU-Si/Al 40) used for the TTiP ligand occlusion was manufactured by Zeolyst company. The solutions were prepared using pure ethanol (99\%) and deionized water (purified in MILLI-Q system with a conductivity of $18.2 \mathrm{M} \Omega \mathrm{cm}$ ). Prior to use the sulfite solutions were carefully prepared and standardized just prior to use. For low concentration solutions, the dilution method was used. sensor in electroanalysis [18].

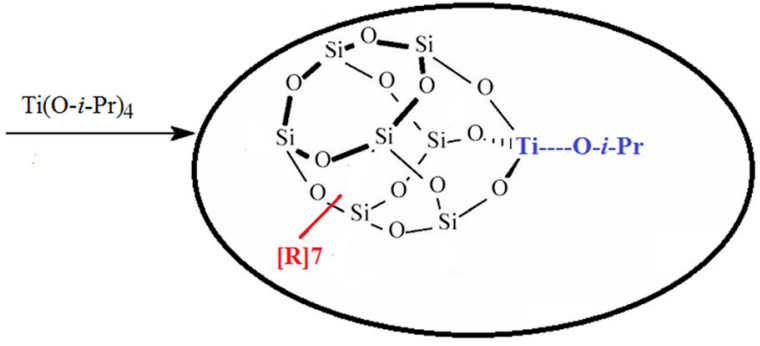

(2)

\subsection{TTiP Occlusion in H-FAU-Si/AI 40}

In a flask were added $25 \mathrm{~mL}$ of tetrahydrofuran (THF), $400 \mathrm{mg}$ of cyclohexyl trisilanol-POSS $(1,3,5,7,9,11,14-$ Heptacyclohexyltricyclo [7.3.3.1 $\left.1^{5.11}\right]$ heptasiloxane-3, 7,14-triol) (Fig. 1(1)) and $0.12 \mathrm{~mL}$ of titanium (IV) isopropoxide. The solution was stirred for $6 \mathrm{~h}$ at a temperature of $50{ }^{\circ} \mathrm{C}$. Subsequently, $2.00 \mathrm{~g}$ of H-FAU-Si / Al 40 (Z) was added to the system and the stirring was continued for a further $6 \mathrm{~h}$ at $50^{\circ} \mathrm{C}$. The material was allowed to stand for $20 \mathrm{~h}$, and then the mixture was slowly filtered by gravity. The obtained material was washed with THF and dried at



Fig. 2 Vibrational spectra of a Z, b ZTTiP and $\mathbf{c}$ ZTTiPNiH 
$60{ }^{\circ} \mathrm{C}$. The Fig. 1, shows the corner capping reaction of cyclohexyl trisilanol-POSS with titanium (IV) isopropoxide (Fig. 1 (2)).

In a second step, $100 \mathrm{~mL}$ of phosphoric acid $(1.00$ mol $\mathrm{L}^{-1}$ ) was added to the previous material obtained and the mixture was stirred for $1 \mathrm{~h}$. After standing for $24 \mathrm{~h}$, the solid was filtered by gravity, washed with deionized water and dried at $100{ }^{\circ} \mathrm{C}$. The product was described as ZTTiP and stored sheltered from light.

\subsection{Adsorption of $\mathrm{Ni}$ (II) and Succeeding Interaction with Potassium Hexacyanoferrate(III): (ZTTiPNiH)}

$1.50 \mathrm{~g}$ of ZTTiP was dissolved in $50 \mathrm{~mL}$ of hydroalcoholic solution $(50 \% \mathrm{v} / \mathrm{v})$ of nickel chloride $\left(0.10 \mathrm{~mol} \mathrm{~L}^{-1}\right)$. The system was kept under stirring for $3 \mathrm{~h}$ at room temperature, and then the solid phase was filtered by gravity, washed with water/ethanol. The material obtained (ZTTiPNi) was dried at $90{ }^{\circ} \mathrm{C}$. In a complementary step, the ZTTiPNi was added to $50 \mathrm{~mL}$ of potassium hexacyanoferrate (III) $\left(0.10 \mathrm{~mol} \mathrm{~L}^{-1}\right)$ and left to stand by for $15 \mathrm{~h}$, then the solid phase was separated by vacuum filtration, washed with deionized water/acetone and dried at $70{ }^{\circ} \mathrm{C}$. The material was stored away from the light and described as ZTTiPNiH.

\section{Techniques}

Fourier transform infrared spectra were recorded on a Nicolet 5DXB FT-IR 300 spectrometer using KBr pellets.
The materials microstructure was obtained using a JEOL JSM T-300 microscope) after coating with gold thin film in Sputter Coater Bal-Tec SCD-050. The materials morphology was examined using a scanning electron microscope (SEM) model (Philips XL 30. The X-ray diffraction patterns (XRD) were obtained using a Siemens D 5000 diffractometer with $\mathrm{CuK} \alpha$ radiation $\lambda=1.5406 \AA$, submitted to $40 \mathrm{KV}, 30 \mathrm{~mA}, 0.05^{\circ} \mathrm{s}^{-1}$ and exposed to radiation from 5 up to $30^{\circ}(2 \theta)$. Cyclic voltammograms were performed using the Auto Lab (PGSTAT 30-Methron). The graphite paste electrode $(\mathrm{GPE})((\phi)=0.5 \mathrm{~mm})$ with modified material was used as working electrode. The counter and reference electrodes were a platinum wire and $\mathrm{Ag} / \mathrm{AgCl}$ (sat), $\mathrm{KCl}$ (3M) electrodes respectively.

\section{Results and Discussion}

Figure 2 illustrates the vibrational spectra of (a): Z, (b): ZTTiP and (c): ZTTiPNiH. All spectra show a broadband in the region of $3460 \mathrm{~cm}^{-1}$ due to the $\mathrm{O}-\mathrm{H}$ bond of the silanol groups and adsorbed water molecules. The deformation vibrations of adsorbed water molecules could be seen at $1636 \mathrm{~cm}^{-1}$. In the spectrum of $\mathrm{Z}$ (Fig. 2a), intense bands in the range of $950-1200 \mathrm{~cm}^{-1}$ are due to $\mathrm{Si}(\mathrm{Al})-\mathrm{O}$ stretching vibrations, which is dependent of the $\mathrm{Al}: \mathrm{Si}$ ratio of the sample. The two bands related to the Si-O-Si and Al-O$\mathrm{Si}$ bridges can be found at the $690-800 \mathrm{~cm}^{-1}$ region. For the ZTTiP and ZTTiPNiH spectra, all bands from their precursors ( $\mathrm{Z}$ and TTiP) [33] can be observed, in addition
Fig. 3 Micrographs of $\mathbf{a} \mathrm{Z}$ $(50,000 X)$, b ZTTiP $(50,000 X)$ and $\mathbf{c}$ ZTTiPNiH $(50,000 \mathrm{X})$

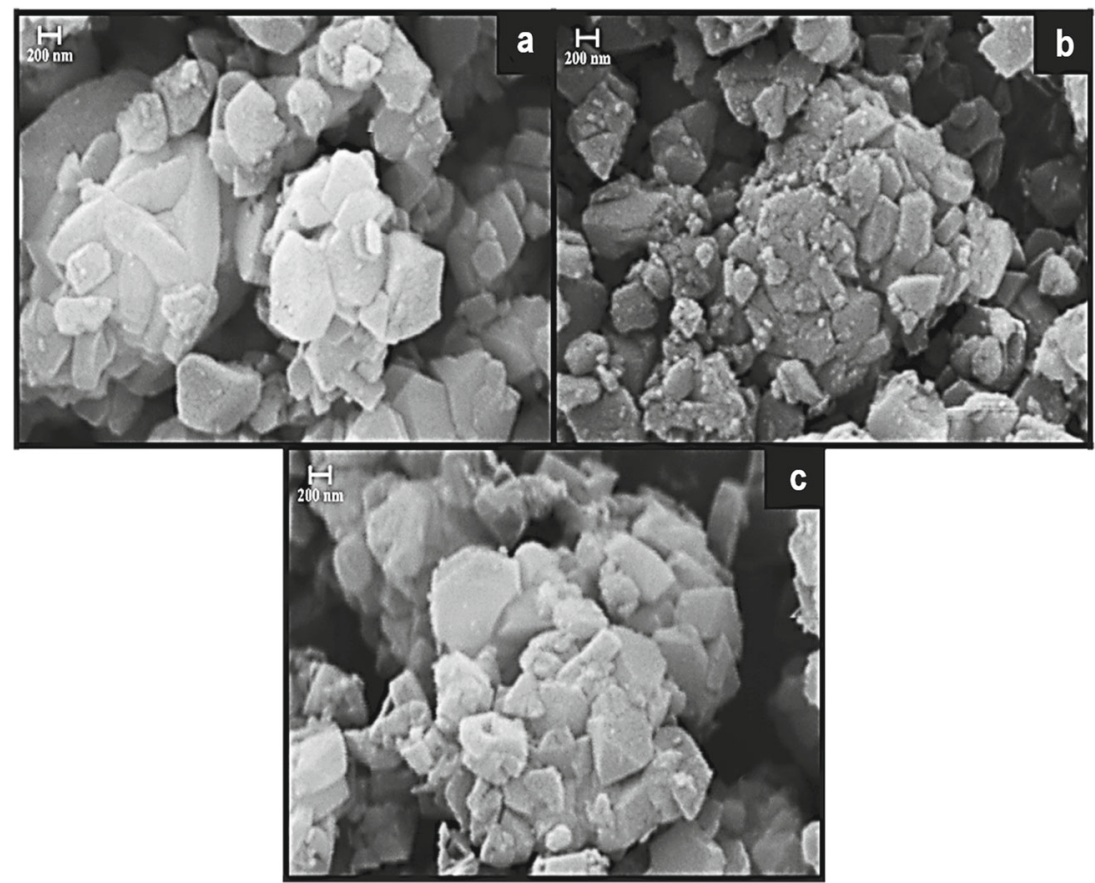



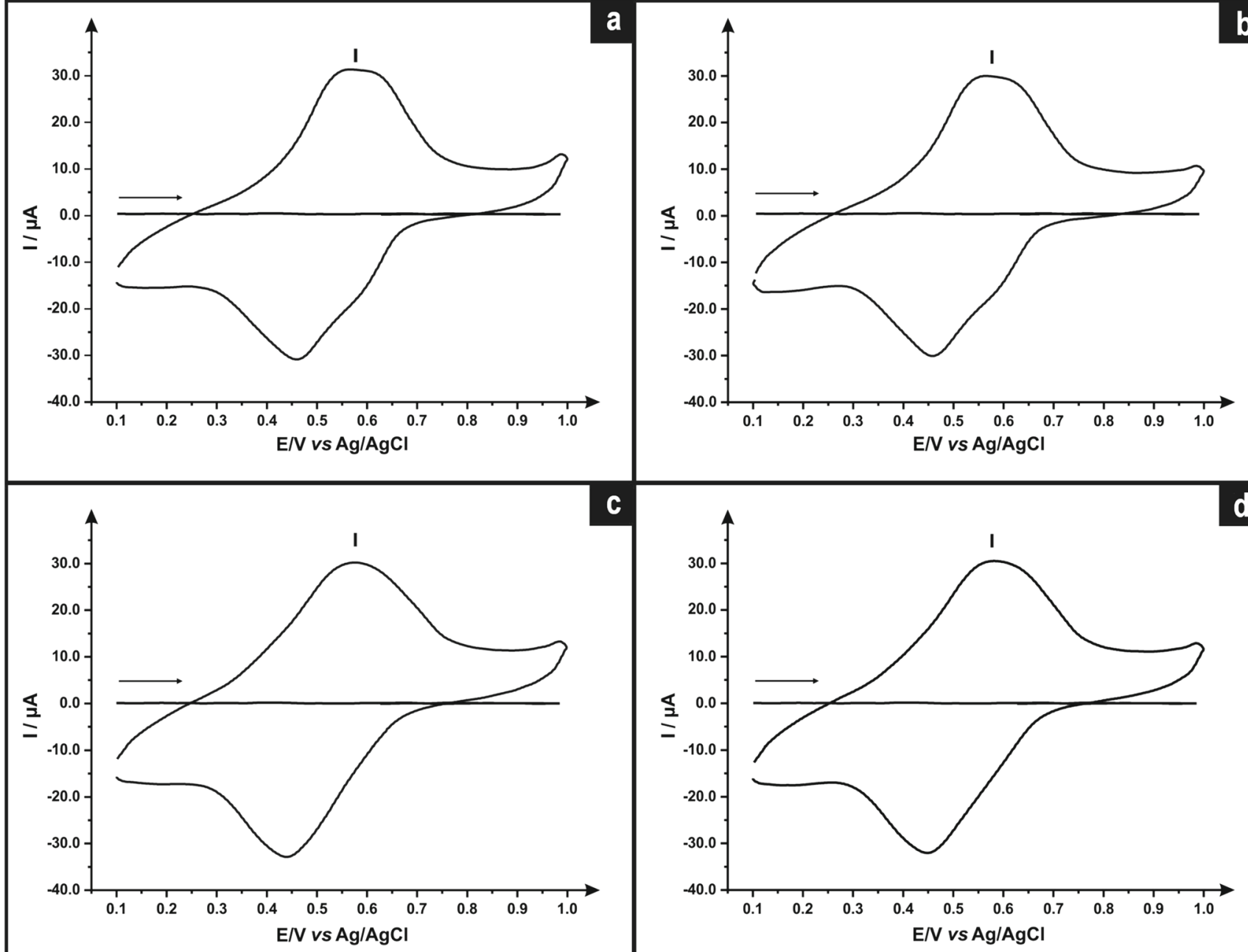

C
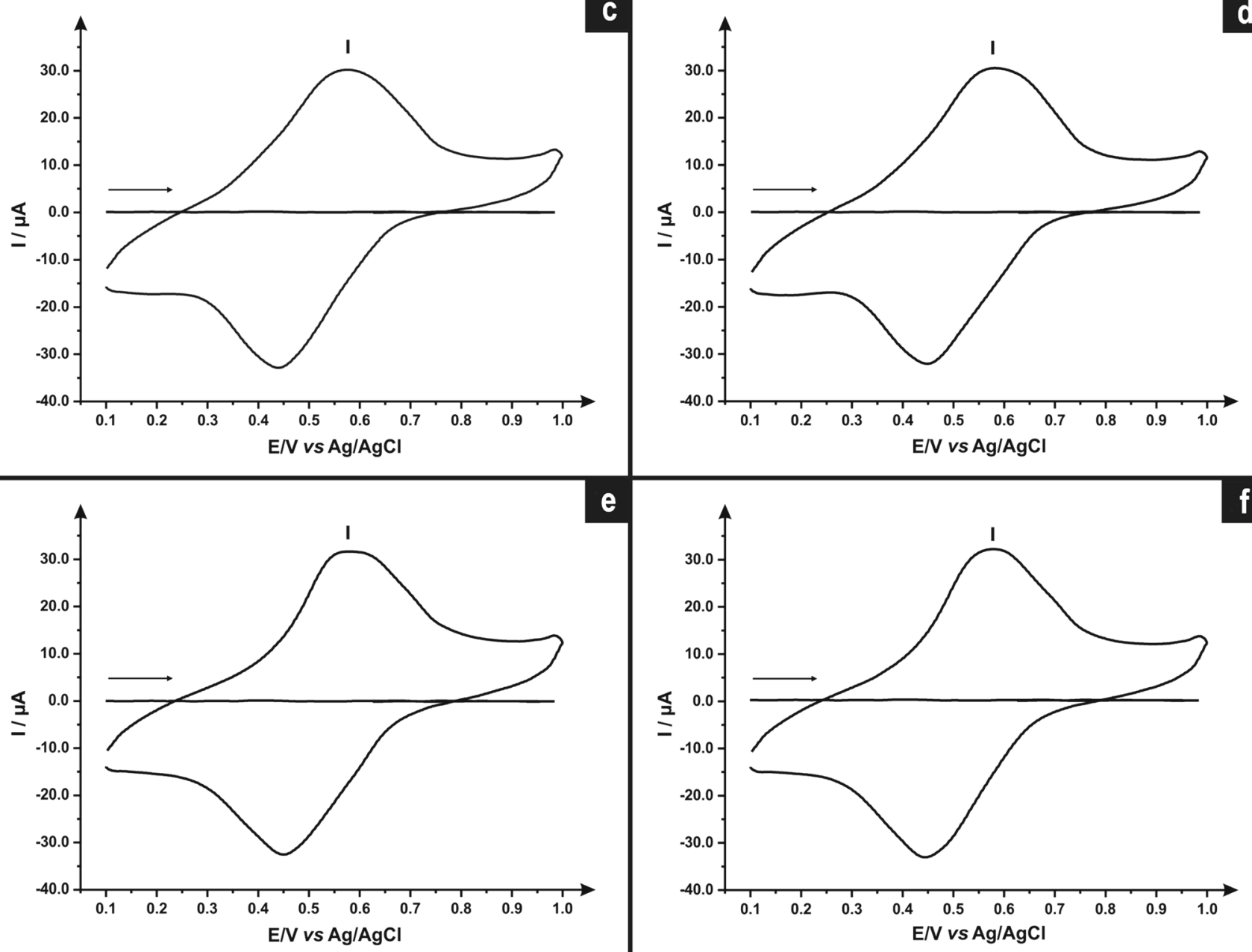

e

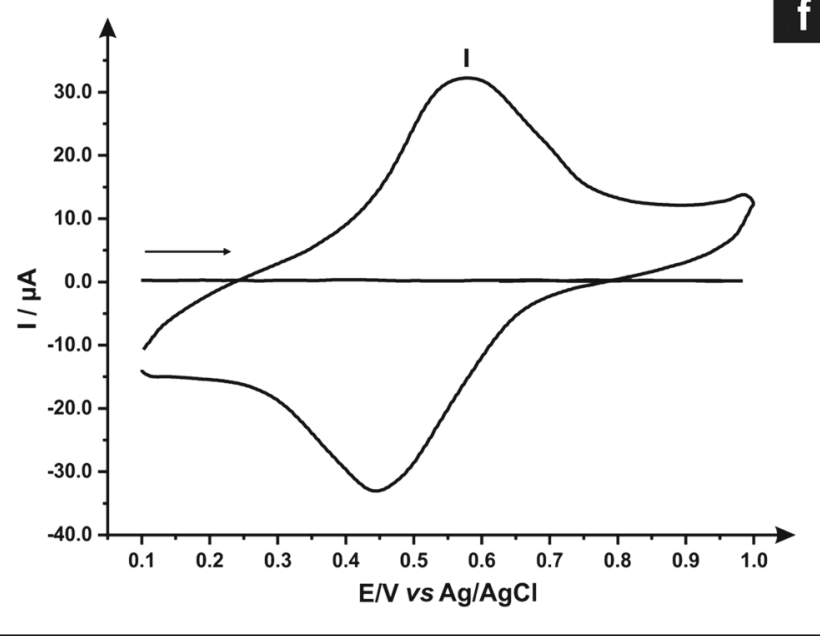

Fig. 4 Influence of the nature of the cations and anions on the GPE modified with $\mathrm{ZTTiPNiH}_{\mathbf{a}} \mathbf{\mathrm { KCl }}, \mathbf{b} \mathrm{KNO}_{3}, \mathbf{c ~ N a C l}, \mathbf{d ~ N a N O}, \mathbf{e ~} \mathrm{NH}_{4} \mathrm{Cl}$ and $\mathbf{f}$ $\mathrm{NH}_{4} \mathrm{NO}_{3}\left(1,00 \mathrm{~mol} \mathrm{~L}^{-1}, \mathrm{v}=20 \mathrm{mv} \mathrm{s}^{-1}\right)$

to two bands more intense between $2750 \mathrm{~cm}^{-1}$ and 2900 $\mathrm{cm}^{-1}$ corresponding to the $v(\mathrm{C}-\mathrm{H})$ stretch observed for TTiP. The bands differing ZTTiPNiH from the other spectra 
Table 1 Electrochemical parameters of ZTTiPNiH (1.00 mol L ${ }^{-1} ; 20$ $\mathrm{mV} \mathrm{s}^{-1}$ )

\begin{tabular}{lllll}
\hline Electrolyte & $\left(\mathrm{I}_{p a} / \mathrm{I}_{p c}\right)$ & $\left(\mathrm{E}^{\circ}\right)(\mathrm{V})^{*}$ & $\begin{array}{l}(\Delta \mathrm{Ep}) \\
(\mathrm{V})^{* *}\end{array}$ & $\begin{array}{l}\text { Diameter of hydrated } \\
\text { cation }[39](\mathrm{nm})\end{array}$ \\
\hline $\mathrm{KCl}$ & 0.66 & 0.51 & 0.10 & 0.24 \\
$\mathrm{KNO}_{3}$ & 0.78 & 0.51 & 0.10 & 0.24 \\
$\mathrm{NaCl}$ & 0.57 & 0.50 & 0.11 & 0.36 \\
$\mathrm{NaNO}_{3}$ & 0.59 & 0.52 & 0.13 & 0.36 \\
$\mathrm{NH}_{4} \mathrm{Cl}$ & 0.72 & 0.52 & 0.13 & 0.25 \\
$\mathrm{NH}_{4} \mathrm{NO}_{3}$ & 0.69 & 0.51 & 0.14 & 0.25 \\
\hline
\end{tabular}

$* \mathrm{E}^{\mathrm{ol}}(\mathrm{V})=\left(\mathrm{E}_{\mathrm{pa}}+\mathrm{E}_{\mathrm{pc}}\right) / 2$

$* * \Delta \mathrm{Ep}(\mathrm{V})=\left|\mathrm{E}_{\mathrm{pa}}-\mathrm{E}_{\mathrm{pc}}\right|$

The micrographs of (a): Z, (b): ZTTiP and (c): ZTTiPNiH with a magnification of 50,000X are shown in Fig. 3. For $\mathrm{Z}$, agglomerations of different particle sizes, in the range of 250 to $550 \mathrm{~nm}$, were observed. ZTTiP micrographs showed no change in particle size when compared to $\mathrm{Z}$ micrographs. ZTTiPNiH micrographs showed a slight increase in particle size of about $50 \mathrm{~nm}$ due to particle agglomeration on the outer surface of the material.

The semi-quantitative centesimal composition of the elements presents in the sample ZTTiPNiH were obtained by X-ray dispersive energy spectroscopy for all constituent elements such as, $\mathrm{C}$; $\mathrm{O}$; $\mathrm{Si}$; $\mathrm{Al}$; $\mathrm{Ti}$; $\mathrm{P} ; \mathrm{Ni}$; Fe, and $\mathrm{K}$ were $7.06 ; 64.09 ; 27.73 ; 0.37 ; 10.16 ; 0.25 ; 0.10 ; 0.08 ; 0.17$. (\% At). The unexpected presence of potassium reinforces the idea of a crystalline reticulum formed by the $\mathrm{NiHCF}$ inside the zeolite cavity. The presence of potassium plays an important role in the redox process of the metal complex formed.
A detailed study was carried out on the electrochemical behavior of GPE modified with ZTTiPNiH employing the cyclic voltammetry method. Figure 4 shows the cyclic voltammogram of GPE with ZTTiPNiH (20\% w/w) on different supporting electrolytes. In all electrolytes, the cyclic voltammogram exhibited a well-defined couple (peak I) with formal potential $\left(\mathrm{E}^{\circ \prime}\right)$ equal to $+0.51 \mathrm{~V}$ assigned to the redox process $\mathrm{Fe}^{+2}(\mathrm{CN})_{6} / \mathrm{Fe}^{+3}(\mathrm{CN})_{6}$ in the presence of $\mathrm{Ni}^{2+}[37,38] \mathrm{So}$, it was possible to notice the influence of the cation effect $\left(\mathrm{NH}_{4}^{+}, \mathrm{Na}^{+}\right.$, and $\left.\mathrm{K}^{+}\right)$and anion $\left(\mathrm{NO}_{3}^{-}\right.$and $\mathrm{Cl}^{-}$) in the oxidation-reduction process of the system.

The Prussian blue analogs have a cubic threedimensional network structure, where the entry of cations with hydrated ionic diameters smaller than the channel diameters of the zeolitic structure occurs, which makes the electro-activity and selectivity dependent on the electrolyte used. In these studies, it was verified that the nature of the ions did not significantly affect the formal potential $\left(\mathrm{E}^{\circ \prime}\right)$, neither the current intensity of anodic/cathodic peak, indicating that the channels of the reticulum formed are larger than the radii diameters of the hydrated cations of the electrolytes tested.

The basic voltammetric parameters obtained from the GPE modified with ZTTiPNiH in different support electrolytes are listed in Table 1 . The results presented suggest that the $\mathrm{Ni}^{\mathrm{II}} \mathrm{Fe}^{\mathrm{II}}(\mathrm{CN})_{6} / \mathrm{Ni}^{\mathrm{II}} \mathrm{Fe}^{\mathrm{III}}(\mathrm{CN})_{6}$ process is quasi-reversible.

The $\mathrm{KNO}_{3}$ electrolyte was chosen for further studies as it presents a well-defined voltammetric performance and great chemical stability when compared to the parameters of the other support electrolytes studied.

Voltammetric performance of GPE modified with ZTTiPNiH at distinct concentrations of $\mathrm{KNO}_{3}$ (from 1.00

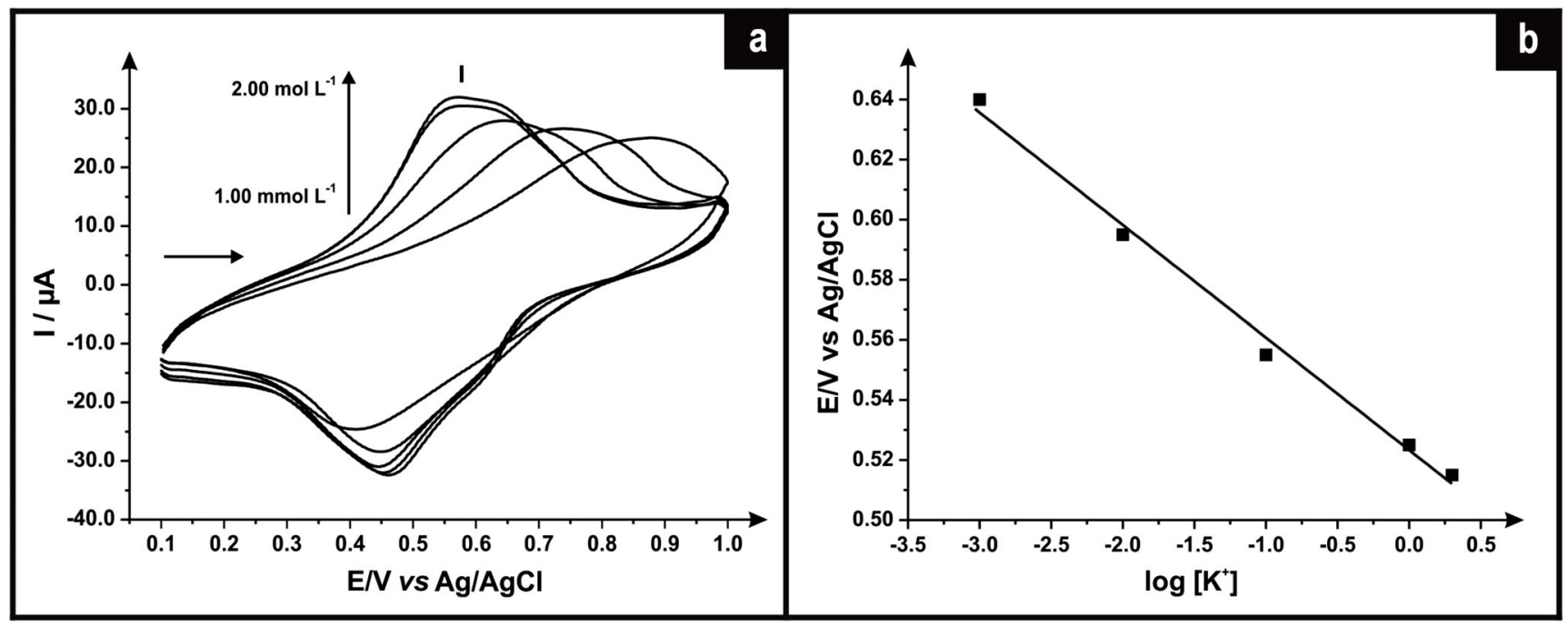

Fig. 5 a Cyclic voltammogram of GPE modified with ZTTiPNiH at different concentrations $\left(\mathrm{KNO}_{3}, \mathrm{v}=20 \mathrm{mV} \mathrm{s}\right.$, $\left.20 \% \mathrm{~m} / \mathrm{m}\right)$ e b Medium Potential $\left(\mathrm{E}^{\circ \prime}\right)$ of graphite paste modified with $\mathrm{ZTTiPNiH}$ as a function of the logarithm of the concentration of $\mathrm{KNO}_{3}$ 


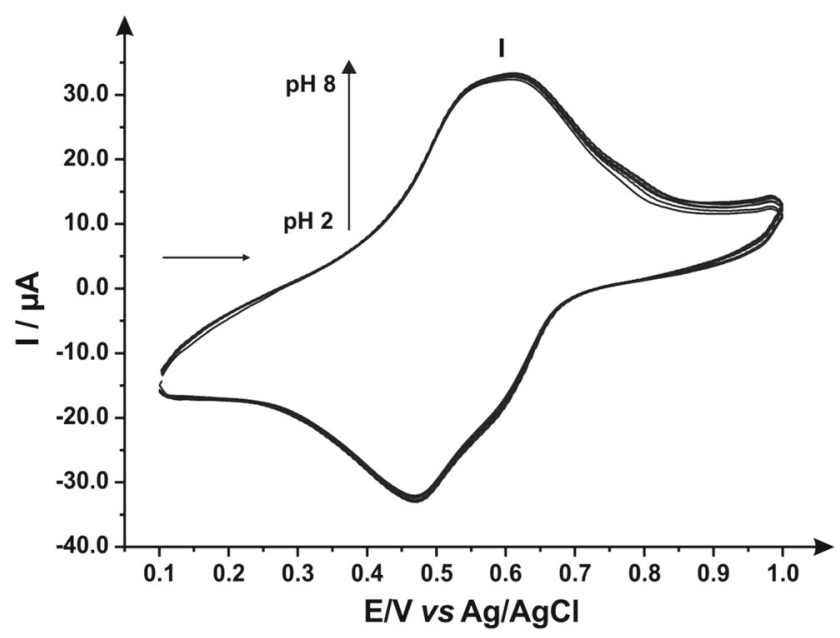

Fig. 6 Cyclic voltammogram of GPE electrode modified with ZTTiPNiH at different $\mathrm{pH}$ values $(2-8)$; $\left(\mathrm{KNO}_{3} 1,00 \mathrm{~mol} \mathrm{~L}^{-1}, \mathrm{v}=\right.$ $20 \mathrm{mV} \mathrm{s}^{-1}$ )

mmol L $\mathrm{L}^{-1}$ to $2.00 \mathrm{~mol} \mathrm{~L}^{-1}$ ) are shown in Fig. 5a. As the electrolyte concentration increased, a rise in the current intensity of the anode / cathode peaks (I) and a pronounced displacement of the formal potential to more negative regions were observed, so it can be noticed the oxidation is favored when the concentration of the $\mathrm{K}^{+}$ion is sufficiently high, so that $\mathrm{E}^{\mathrm{ol}}$ is lower in higher concentrations of $\mathrm{K}^{+}$. This atypical behavior was attributed to the high ionic strength and also to a change in the activity of these ions [40].

The plot of the formal potential $\left(\mathrm{E}^{\circ}\right)$ as a function of the logarithm $(\log )$ of the concentration of $\mathrm{KNO}_{3}$ (Fig. 5b), showed a linear response, corroborating that the redox process is dependent on the $\mathrm{K}^{+}$concentration in the solution. The slope was approximately $35 \mathrm{mV} / \mathrm{dec}$ ade of the concentration of $\mathrm{K}^{+}$ions, suggesting that the redox process of this composite involves the participation of two electrons.

In order to optimize the system, and according to the results obtained, the chosen concentration of $\mathrm{KNO}_{3}$ was $1.00 \mathrm{~mol} \mathrm{~L}^{-1}$ for further studies due to the better voltammetric response of the modified GPE.

Additionally, with $\mathrm{pH}$ variation (2 to 8 ) no significant change was observed in the current intensity and $\mathrm{E}^{\circ \prime}$ of peak I (Fig. 6). Thus, it can be stated that the hydrogenionic concentration does not directly affect the electrochemical process and therefore it is not necessary to use a buffer solution.

Taking into account the possibility of carrying out further studies, aiming at the electrocatalytic determination in biological $\mathrm{pH}$, the $\mathrm{pH} 7$ was chosen.

Figure $7 \mathrm{a}$ shows the cyclic voltammograms of the GPE modified with ZTTiPNiH at scanning rates of 10 to $100 \mathrm{mV} \mathrm{s}^{-1}$. As the system scanning rate increased, anodic/cathodic peak current increased, a slight displacement of the medium potential $\left(\mathrm{E}^{\circ \prime}\right)$ of $40 \mathrm{mV}$ for positive regions and a potential variation $(\Delta \mathrm{Ep})$ of $80 \mathrm{mV}$. Figure $7 \mathrm{~b}$ shows a linear relationship between the current peak I (anode/cathode) and the square root of the scanning rate, thus characterizing a diffusional process $[41,42]$.

The peak separation potentials $(\Delta \mathrm{Ep})$ and the formal potential $\left(\mathrm{E}^{\circ \prime}\right)$ as a function of the logarithm of the square root of scan rate $(\log v)$ is illustrated in Fig. 8. According to Laviron's graphs, two straight lines, one with a slope of $2.3 \mathrm{RT} /(1-\alpha) \mathrm{nF}$ to the anodic peak and the other with a slope of $-2.3 \mathrm{RT} / \alpha \mathrm{nF}$ to the cathodic peak, are obtained. In this way, the value of the electron transfer coefficient $(\alpha)$ of the

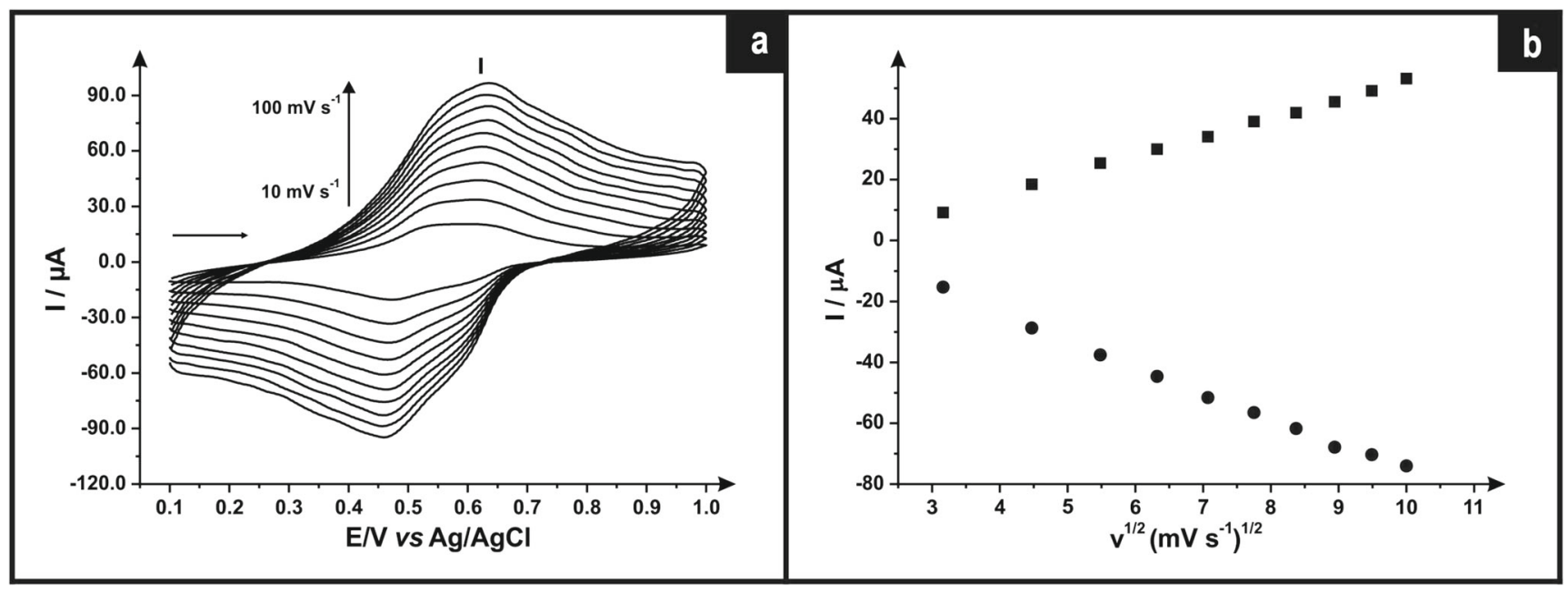

Fig. 7 a Cyclic voltammogram of the GPE electrode modified with ZTTiPNiH at different scanning rates: $10-100 \mathrm{mV}^{-1} ;\left(\mathrm{KNO}_{3} 1,00 \mathrm{~mol} \mathrm{~L}^{-1}\right.$; $\mathrm{pH} 7,0$ ) e b Dependence of the current intensity of the peak I (anodic and cathodic) with the square root of the scan ratio 




Fig. 8 Straight Equations of Laviron's graphs, Epa and Epc minus the formal potential $\left(\mathrm{E}^{\circ}\right) \mathrm{vs}$. $\log \mathrm{v}$

ZTTiPNiH was approximately 0.59. In ideal systems, the value of the electron transfer coefficient is equal to 0.50 , but there is an acceptable margin of error of $0.30 \leq \alpha \leq 0.70$ [43].

The value of the charge transfer constant (ks) was determined by the Laviron's equation (1). This equation satisfies the conditions $(200 \mathrm{mV}) / \mathrm{n}<\Delta \mathrm{Ep}<(200 \mathrm{mV}) / \mathrm{n}$, besides being able to be applied for high and low scanning rates [40].

$\log k s=\alpha \log (1-\alpha)+(1-\alpha) \log \alpha \log \left(\frac{R T}{n F v}\right)-\alpha(1-\alpha) n F \frac{\Delta E p}{2,3 R T}$

where: $\alpha=$ electron transfer coefficient, $\mathrm{T}=298 \mathrm{~K}, \mathrm{~F}=$ 96485.3399 $\mathrm{C} \mathrm{mol}^{-1}$ (Faraday's constant), $\mathrm{R}=8.3 \mathrm{~J} \mathrm{~K}^{-1}$ $\mathrm{mol}^{-1}$ (universal constant of a perfect gas), $\mathrm{n}=$ number of electrons transferred e $v=$ scanning ratio. Using Eq. 1, the value of charge transfer constant (ks) obtained was equal to $0.35 \mathrm{~s}^{-1}$. The values found for $\alpha$ and ks are very close to those found in the literature for $\mathrm{NiH}$ [44]. The scanning rate chosen for subsequent studies was $30 \mathrm{mV} \mathrm{s}^{-1}$.

\subsection{Application of the Material in the Sulfite Catalytic Electrooxidation}

Cyclic voltammograms of the catalytic electrooxidation of the sulfite using a GPE modified with ZTTiPNiH are shown in Fig. 9. It was observed that the modified GPE in the presence of sulfite (a) showed an increase in the current intensity of the anodic peak and a decrease in the current of the cathodic peak, in relation to the modified electrode in the absence $\left(\mathrm{E}^{\prime \prime}=+0.53 \mathrm{~V}\right)$ of sulfite $(\mathrm{b})$, thus proving the occurrence of the catalytic electrooxidation of the analyte.

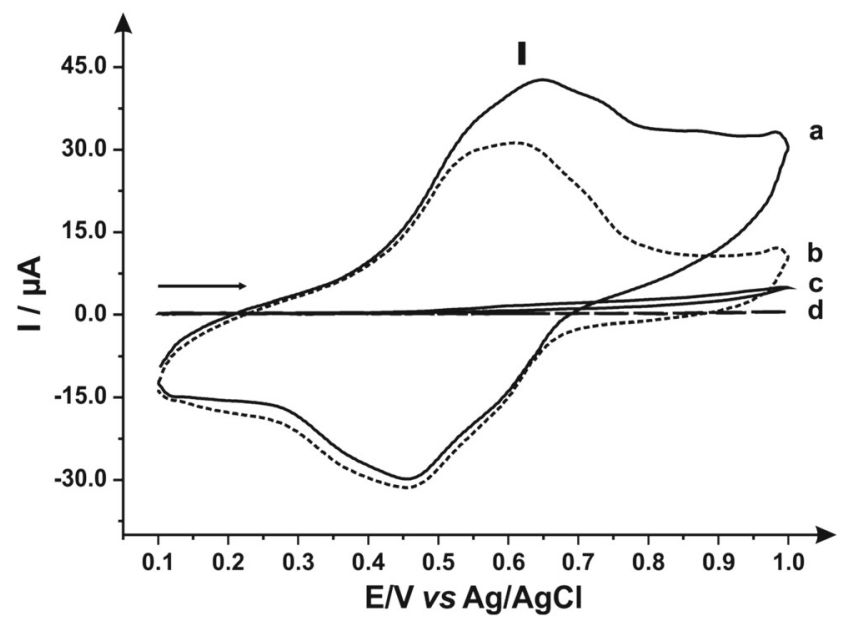

Fig. 9 Cyclic voltammograms of a GPE with ZTTiPNiH in presence of $0,8 \mathrm{mmol} \mathrm{L}^{-1}$ of sulfite and $\mathbf{b}$ in absence of sulfite $\mathbf{c}$ unmodified GPE in presence of $0,8 \mathrm{mmol} \mathrm{L}^{-1}$ of sulfite and $\mathbf{d}$ in absence of sulfite $\left(\mathrm{KNO}_{3} 1,0 \mathrm{~mol} \mathrm{~L}^{-1} ; \mathrm{pH}=7,0 ; \mathrm{v}=30 \mathrm{mV} \mathrm{s}^{-1}\right)$

The unmodified GPE in the presence (c) and absence (d) of sulfite did not present any voltammetric response at the potential window studied $(0.1$ to $1.0 \mathrm{~V})$.

The current intensity of the anodic peak increases linearly with increasing sulfite concentration in the electrolytic solution. The $\mathrm{Fe}^{3+}$ produced during the anodic scan chemically oxidizes the $\mathrm{SO}_{3}^{2-}$ in $\mathrm{SO}_{4}^{2-}$, while it is reduced to $\mathrm{Fe}^{2+}$, which should subsequently be electrochemically oxidized to $\mathrm{Fe}^{3+}$ on the surface of the electrode. The Eqs. 2 and 3 represent the electrochemical stage (ES) and the chemical stage (CS), respectively.

$$
\mathrm{K}_{2} \mathrm{Ni}^{(\mathrm{II})}\left[\mathrm{Fe}^{(\mathrm{II})}(\mathrm{CN})_{6}\right] \leftrightarrow 2 \mathbf{\mathrm { mNi }}{ }^{(\mathrm{II})}\left[\mathrm{Fe}^{(\mathrm{III})}(\mathrm{CN})_{6}\right]+2 \mathrm{e}^{-}+2 \mathrm{~K}^{+}
$$

$$
\begin{aligned}
& 2 \mathrm{KNi}^{(\mathrm{II})}\left[\mathrm{Fe}^{(\mathrm{III})}(\mathrm{CN})_{6}\right]+2 \mathrm{~K}^{+}+\mathrm{SO}_{3}^{2-}+\mathrm{H}_{2} \mathrm{O} \\
& \leftrightarrow 2 \mathrm{~K}_{2} \mathrm{Ni}^{(\mathrm{II})}\left[\mathrm{Fe}^{(\mathrm{II})}(\mathrm{CN})_{6}\right]+2 \mathrm{H}^{+}+\mathrm{SO}_{4}^{2-}
\end{aligned}
$$

where, $\mathbf{\square}=$ ZTTiP.

Figure 10a shows the cyclic voltammograms of GPE modified with ZTTiPNiH at different sulfite concentrations. After the additions, the ZTTiPNiH system showed an increase in the current intensity of the anodic peak and a small displacement of the $\mathrm{E}^{\circ \prime}$ for anodic regions. By the analytical curve obtained from the anodic current intensity of peak I as a function of sulfite concentration (Fig. 10b), a linear response was obtained in a concentration range of 0.05 to $0.8 \mathrm{mmol} \mathrm{L}^{-1}$ with a corresponding equation of Ip $(\mu \mathrm{A})=14.42 \mathrm{~mA} \mathrm{~L} \mathrm{~mol}{ }^{-1}\left[\mathrm{mmol} \mathrm{L}^{-1}\right]+17.14 \mu \mathrm{A}$ and a correlation coefficient of 0.993 . The method presented a detection limit $(3 \sigma)$ of $0.05 \mathrm{mmol} \mathrm{L}^{-1}$ with a relative standard deviation of $4.21 \%(\mathrm{n}=3)$ and an amperometric sensitivity of $14.42 \mathrm{~mA} \mathrm{~L} \mathrm{~mol}^{-1}$ for sulfite. 

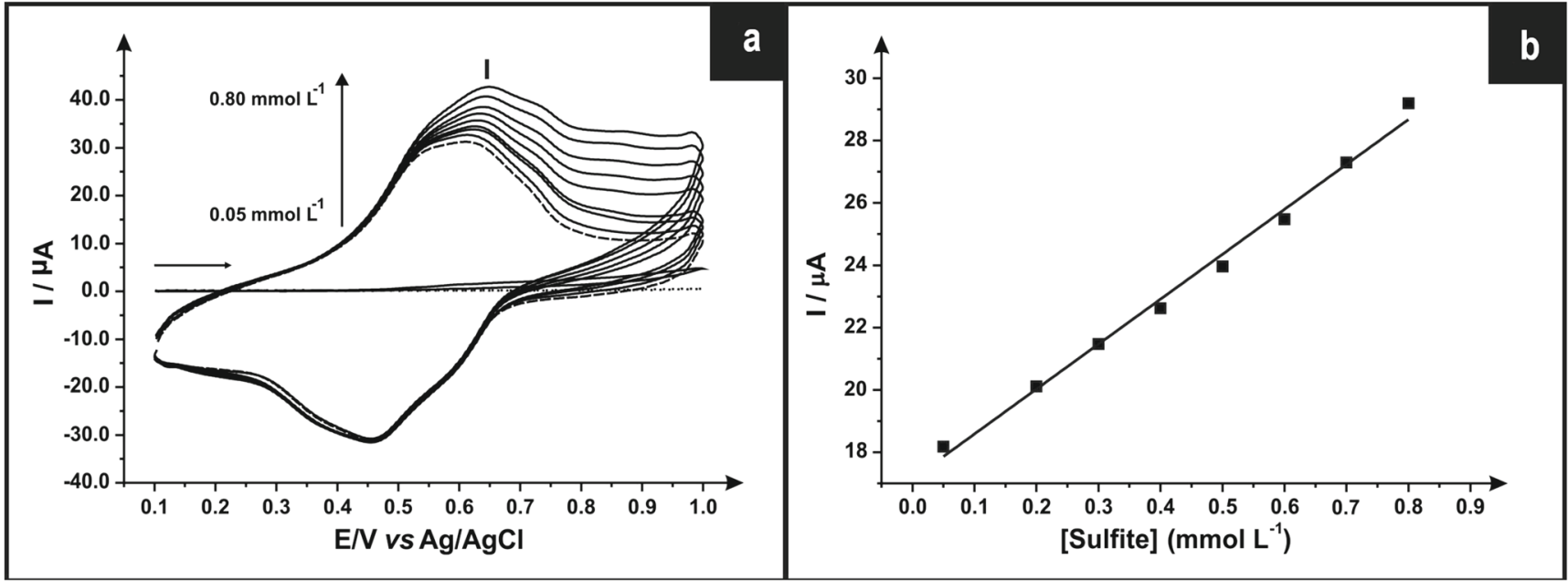

Fig. 10 a Cyclic voltammograms of the applications of various sulfite concentrations using the GPE with ZTTiPNiH; $\mathbf{b}$ The Analytical curve of the anodic peak for sulfite determination using GPE with ZTTiPNiH. $\left(\mathrm{KNO}_{3} 1.00 \mathrm{~mol} \mathrm{~L}^{-1}, \mathrm{pH} 7.0 ; \mathrm{v}=30 \mathrm{mV} \mathrm{s}^{-1}\right)$

\section{Conclusion}

Titanium (IV) trisilanol POSS (TiP) was occluded into the H-FAU zeolite and characterized by FTIR, microscopy, EDX. The occluded material was reacted firstly with phosphate (ZTTiP) then with Nickel and subsequent with potassium hexacyanoferrate (III) to form a metal complex into the zeolite cavity (ZTTiPNiH). A redox couple corresponding to the $\mathrm{Ni}^{\mathrm{II}} \mathrm{Fe}^{\mathrm{II}}(\mathrm{CN})_{6} / \mathrm{Ni}^{\mathrm{II}} \mathrm{Fe}^{\mathrm{III}}(\mathrm{CN})_{6}$ was characterized by cyclic voltammetry and the GPE with ZTTiPNiH was applied for facile and rapid detection of sulfite. From the analytical curve, a linear response was obtained in a concentration range of 0.05 to 0.8 mmol L $\mathrm{L}^{-1}$ with a corresponding equation of $\operatorname{Ip}(\mu \mathrm{A})=$ $14.42 \mathrm{~mA} \mathrm{~L} \mathrm{~mol}{ }^{-1}\left[\mathrm{mmol} \mathrm{L}^{-1}\right]+17.14 \mu \mathrm{A}$ and a correlation coefficient of 0.993 . The method presented a detection limit $(3 \sigma)$ of $0.05 \mathrm{mmol} \mathrm{L}^{-1}$ with a relative standard deviation of $4.21 \%(\mathrm{n}=3)$ and an amperometric sensitivity of $14.42 \mathrm{~mA} \mathrm{~L} \mathrm{~mol}^{-1}$ for sulfite. The use of the electrochemical system containing ZTTiPNiH employed for the detection of sulfite, in comparison with other known analytic methods, is advantageous for the following reasons: a) it does not require any prior chemical treatment, b) it is easily confection, allowing the surface to be quickly renewed thereby decreasing the time for its quantification.

Funding Information The authors would like to express their gratitude for the financial support by the Fundação de Amparo à Pesquisa do Estado de São Paulo (FAPESP- Proc. 2012/05438-1 and Coordenação de Aperfeiçoamento de Pessoal de Nível Superior (CAPES).

\section{Compliance with Ethical Standards}

Conflict of interest The authors declare that they have no conflict of interest.

\section{References}

1. Brown JF, Vogt LH, Prescott PI (1964) Preparation and characterization of the lower equilibrated phenylsilsesquioxanes. J Am Chem Soc 86(6):1120-1125. https://doi.org/10.1021/ja01060a033

2. Brown JF, Vogt LH (1965) The polycondensation of cyclohexylsilanetriol. J Am Chem Soc 87(19):4313-4317. https://doi.org/10. 1021/ja00947a016

3. Voronkov MG, Lavrent'yev VL (1982) Polyhedral oligosilsesquioxanes and their homo derivatives. Top Curr Chem 102:199236. https://doi.org/10.1007/3-540-11345-2_12

4. Abbenhuis HCL (2000) Advances in homogeneous and heterogeneous catalysis with metal-containing silsesquioxanes. Chem Eur J 6(1):25-32. https://doi.org/10.1002/(SICI)1521-3765(20000103) 6:1<25::AID-CHEM25>3.0.CO;2-Y

5. Feher FJ, Budzichowski TA (1995) Silsesquioxanes as ligands in inorganic and organometallic chemistry. Polyhedron: Polyhedron 14(22):3239-3253. https://doi.org/10.1016/0277-5387(95)85009-0

6. Harrison PG (1997) Silicate cages: precursors to new materials. J Organomet Chem 542(2):141-183. https://doi.org/10.1016/S0022328X(96)06821-0

7. Feher FJ, Tajima TL (1994) Synthesis of a molybdenumcontaining silsesquioxane which rapidly catalyzes the metathesis of olefins. J Am Chem Soc 116(5):2145-2146. https://doi.org/10. 1021/ja00084a065

8. Hermann WA, Anwander R, Dufaud V, Scherer W (1994) Molekulare Siloxankomplexe der Seltenerdmetalle - Modellsysteme für silicatgeträgerte Katalysatoren? Angew Chem 106(12):1338-1340. https://doi.org/10.1002/ange.19941061221

9. Hermann WA, Anwander R, Dufaud V, Scherer W (1994) Molecular siloxane complexes of rare earth metals-model systems for silicate-supported catalysts? Angew Chem Int Ed Engl 33(12):1285-1286. https://doi.org/10.1002/anie.199412851

10. Liu J-C, Wilson SR, Shapley JR, Feher FJ (1990) A triosmium cluster-siloxane cage complex. Synthesis and structure of $\mathrm{HOs}_{3}(\mathrm{CO})_{10}\left[(. \mathrm{mu} .-\mathrm{O}) \mathrm{Si}_{7} \mathrm{O}_{10}\left(\mathrm{C}_{6} \mathrm{H}_{11}\right)_{7}\right]$. Inorg Chem 29(26):5138-5139. https://doi.org/10.1021/ic00351a002

11. Buys IE, Hambley TW, Houlton DJ, Maschmeyer T, Masters AF, Smith AK (1994) Models of surface-confined metallocene derivatives. J Mol Catal 86(1-3):309-318. https://doi.org/10.1016/03045102(93)E0177-I 
12. Jefferson L-CU, Netchaev AD, Jefcoat JA, Windham AD, McFarland FM, Guo S, Buchanan RK, Buchanan JP (2015) Preparation and characterization of polyhedral oligomeric silsesquioxanecontaining, Titania-Thiol-Ene composite photocatalytic coatings, emphasizing the hydrophobic-hydrophilic transition. ACS Appl Mater Interfaces 7(23):12639-12648. https://doi.org/10.1021/acsami. $5 \mathrm{~b} 01488$

13. Bai H, Zheng Y, Li P, Zhang A (2015) Synthesis of liquid-like trisilanol isobutyl-POSS NOHM and its application in capturing $\mathrm{CO}_{2}$. Chem Res Chin Univ 31(3):484-488. https://doi.org/10.1007/ s40242-015-4443-5

14. Perše LS, Mihelčič M, Orel B (2015) Rheological and optical properties of solar absorbing paints with POSS-treated pigments. Mater Chem and Phys 149-150:368-377. https://doi.org/10.1016/ j.matchemphys.2014.10.031

15. Haddad TS, Viers BD, Phillips SH (2001) Polyhedral oligomeric silsesquioxane (POSS)-styrene macromers. J Inorg Organomet Polym Mater 11(3):155-164. https://doi.org/10.1023/A:10152376 27340

16. Mehta AM, Tembe GL, Parikh PA, Mehta GN (2011) Catalytic ethylene polymerization by the titanium-polyhedral oligomeric silsesquioxane- $\mathrm{Et}_{3} \mathrm{Al}_{2} \mathrm{Cl}_{3}$ system. Reac Kinet Mech Cat 104(2):369-375. https://doi.org/10.1007/s11144-011-0356-6

17. do Carmo DR, Dias Filho NL, Stradiotto NR (2007) Encapsulation of titanium (IV) silsesquioxane into the NH4USY zeolite: preparation, characterization and application. Mater Res Bull 42 (10):1811-1822. https://doi.org/10.1016/j.materresbull.2006.12.001

18. Collman JP, Marroco M, Denisevich P, Koval C, Anson FC (1979) Potent catalysis of the electroreduction of oxygen to water by dicobalt porphyrin dimers adsorbed on graphite electrodes. J Electroanal Chem Interfacial Electrochem 101(1):117-122. https://doi.org/10.1016/S0022-0728(79)80085-6

19. Isaac A, Davis J, Livingstone C, Wain AJ, Compton RG (2006) Electroanalytical methods for the determination of sulfite in food and beverages. Trends Anal Chem 25(6):589-598. https://doi.org/10.1016/j.trac.2006.04.001

20. Schwartz H (1983) Sensitivity to ingested metabisulfite: variations in clinical presentation. J Allergy Clin Inmunol 71(5):487-489. https://doi.org/10.1016/0091-6749(83)90466-9

21. Araújo AN, Couto CMCM, Lima JLFC, Montenegro MCBSM (1998) Determination of $\mathrm{SO}_{2}$ in wines using a flow injection analysis system with potentiometric detection. J Agric Food Chem 46(1):168-172. https://doi.org/10.1021/jf970354i

22. Azevedo CMN, Araki K, Toma HE, Angnes L (1999) Determination of sulfur dioxide in wines by gas-diffusion flow injection analysis utilizing modified electrodes with electrostatically assembled films of tetraruthenated porphyrin. Anal Chim Acta 387(2):175-180. https://doi.org/10.1016/S0003-2670(99)00060-4

23. William S (1984) Official methods of the AOAC, 14th edn. Association of Official Analytical Chemists Inc, Arlington

24. Nour El-Dein FA, Zayed MA, Khalifa H (1989) Some observations on the microdetermination of sulfite, sulfide, and thiosulfate by mercurimetric titration. Microchem J 39(1):126-132. https://doi.org/10.1016/0026-265X(89)90018-0

25. Li Y, Zhao M (2006) Simple methods for rapid determination of sulfite in food products. Food Control 17(12):975-980. https://doi.org/10.1016/j.foodcont.2005.07.008

26. Zare-Dorabei R, Boroun S, Noroozifar M (2018) Flow injection analysis-flame atomic absorption spectrometry system for indirect determination of sulfite after on-line reduction of solidphase manganese (IV) dioxide reactor. Talanta 178:722-727. https://doi.org/10.1016/j.talanta.2017.10.012

27. Perfetti GA, Diachenko GW (2003) Determination of sulfite in dried garlic by reversed phase ion-pairing liquid chromatography with post-column detection. J AOAC Int 86(3):544-550
28. Kim HJ, Kim YK (1986) Analysis of free and total sulfites in food by ion chromatography with electrochemical detection. J Food Sci 51(5):1360-1361. https://doi.org/10.1111/j.1365-2621.1986.tb13 122. $\mathrm{x}$

29. Theisen S, Hänsch R, Kothe L, Leist U, Galensa R (2010) A fast and sensitive HPLC method for sulfite analysis in food based on a plant sulfite oxidase biosensor. Biosens Bioelectron 26(1):175181. https://doi.org/10.1016/j.bios.2010.06.009

30. Preecharueangrit S, Thavarungkul $P$, Kanatharana $P$, Numnuam A (2018) Amperometric sensing of sulfite using a gold electrode coated with ordered mesoporous carbon modified with nickel hexacyanoferrate. J Electroanal Chem 808:150-159. https://doi.org/ 10.1016/j.jelechem.2017.11.070

31. García T, Casero E, Lorenzo E, Pariente F (2005) Electrochemical sensor for sulfite determination based on iron hexacyanoferrate film modified electrodes. Sens Actuators B Chem 106(2):803809. https://doi.org/10.1016/j.snb.2004.09.033

32. Cumba LR, Bicalho UO, Carmo DR (2012) Voltammetric studies of cobalt hexacyanoferrate formed on the titanium (IV) phosphate surface and its application to the determination of sulfite. Int $\mathrm{J}$ of Electrochem Sci 7(3):2123-2135

33. Jerman I, Koželj M, Orel B (2010) The effect of polyhedral oligomeric silsesquioxane dispersant and low surface energy additives on spectrally selective paint coatings with selfcleaning properties. Sol Energy Mater Sol Cells 94(2):232-245. https://doi.org/10.1016/j.solmat.2009.09.008

34. Fang B, Feng Y, Wang G, Zhang C, Gu A, Liu M (2011) A uric acid sensor based on electrodeposition of nickel hexacyanoferrate nanoparticles on an electrode modified with multi-walled carbon nanotubes. Mikrochim Acta 173(1-2):27-32. https://doi.org/10.1007/s00604-010-0509-8

35. Mostafa M, El-Absy MA, Amin M, El-Amir MA, Farag AB (2010) Partial purification of neutron-activation 99Mo from crosscontaminant radionuclides onto potassium nickel hexacyanoferrate(II) column. J Radioanal Nucl Chem 285(3):579-588. https://doi.org/10.1007/s10967-010-0584-7

36. Bagkar N, Betty CA, Hassan PA, Kahali K, Bellare JR, Yakhmi JV (2006) Self-assembled films of nickel hexacyanoferrate: Electrochemical properties and application in potassium ion sensing. Thin Solid Films 497(1-2):259-266. https://doi.org/10.1016/j.tsf.2005.11.002

37. Deng K, Li C, Qiu X, Zhou J, Hou Z (2015) Electrochemical preparation, characterization and application of electrodes modified with nickel-cobalt hexacyanoferrate/graphene oxide-carbon nanotubes. J Electroanal Chem 755:197-202. https://doi.org/10.1016/j.jelechem.2015.08.003

38. Makowski O, Kowalewska B, Szymanska D, Stroka J, Miecznikowski K, Palys B, Malik MA, Kulesza PJ (2007) Controlled fabrication of multilayered 4-(pyrrole-1-yl) benzoate supported poly(3,4-ethylenedioxythiophene) linked hybrid films of Prussian blue-type nickel hexacyanoferrate. Electrochim Acta 53(3):1235-1243. https://doi.org/10.1016/j.electacta.2007.02.083

39. Engel D, Grabner EW (1985) Copper hexacyanoferrate-modified glassy carbon: a novel type of potassium-selective electrode. Ber Bunsenges Phys Chem 89(9):982-986. https://doi.org/10.1002/ bbpc. 19850890911

40. Jayasri D, Narayanan SS (2006) Electrocatalytic oxidation and amperometric determination of BHA at graphite-wax composite electrode with silver hexacyanoferrate as an electrocatalyst. Sens Actuators B Chem 119(1):135-142. https://doi.org/10.1016/j.snb. 2005.11.064

41. Bard AJ, Faulkner LR (2001) Electrochemical methods: fundamentals and applications. Wiley, New York

42. do Carmo DR, Silva RMD, Stradiotto NR (2002) Estudo eletroquímico de $\mathrm{Fe}\left[\mathrm{Fe}(\mathrm{CN})_{5} \mathrm{NO}\right]$ em eletrodo de pasta de grafite. 
Eclet Quim 27:197-210. https://doi.org/10.1590/S0100-46702002 000200017

43. Laviron E (1979) General expression of the linear potential sweep voltammogram in the case of diffusionless electrochemical systems. J Electroanal Chem Interfacial Electrochem 101(1):1928. https://doi.org/10.1016/S0022-0728(79)80075-3
44. Babu RS, Prabhu P, Narayanan SS (2011) Selective electrooxidation of uric acid in presence of ascorbic acid at a room temperature ionic liquid/nickel hexacyanoferrate nanoparticles composite electrode. Colloids Surf B Biointerfaces 88(2):755-763. https://doi.org/10.1016/j.colsurfb.2011.08.011 